Kansas State University Libraries

New Prairie Press

\title{
PREDICTION OF BREEDING VALUES FOR UNMEASURED TRAITS FROM MEASURED TRAITS
}

\author{
Kristin L. Barkhouse \\ L. Dale Van Vleck
}

Follow this and additional works at: https://newprairiepress.org/agstatconference

Part of the Agriculture Commons, and the Applied Statistics Commons

\section{(c) (1) $\Theta(9$}

This work is licensed under a Creative Commons Attribution-Noncommercial-No Derivative Works 4.0 License.

\section{Recommended Citation}

Barkhouse, Kristin L. and Van Vleck, L. Dale (1994). "PREDICTION OF BREEDING VALUES FOR UNMEASURED TRAITS FROM MEASURED TRAITS," Conference on Applied Statistics in Agriculture. https://doi.org/10.4148/2475-7772.1366

This is brought to you for free and open access by the Conferences at New Prairie Press. It has been accepted for inclusion in Conference on Applied Statistics in Agriculture by an authorized administrator of New Prairie Press. For more information, please contact cads@k-state.edu. 


\title{
PREDICTION OF BREEDING VALUES FOR UNMEASURED TRAITS FROM MEASURED TRAITS
}

\author{
Kristin L. Barkhouse ${ }^{*}$ and L. Dale Van Vleck \\ University of Nebraska, Lincoln \\ ARS-USDA, U.S. Meat Animal Research Center \\ Clay Center, NE
}

\begin{abstract}
Henderson $(1977,1984)$ described a method for prediction of breeding values for traits not in the model for records. This method may be practical for animal or sire models for the case when no measurements can be obtained on any animals for some traits to be evaluated. The least squares equations are augmented with $\mathrm{A}^{-1} \otimes \mathrm{G}_{\mathrm{N}}^{-1}$ rather than with $A^{-1} \otimes G_{0}^{-1}$ where $A$ is the numerator relationship and $G_{0}$ and $G_{N}$ are the genetic covariance matrices for measured and for all traits. This method can be used for each unmeasured trait or simultaneously for measured and all unmeasured traits. An option in the MTDFRUN module of the Multiple Trait Derivative Free REML (MTDFREML) program of Boldman et al. (1993) is to obtain solutions for breeding values and their prediction error variances. However, the preparation program (MTDFPREP) must be tricked to set-up equation numbers for breeding values of the unmeasured traits. Adding dummy records for the unmeasured traits but with missing records for the measured traits for dummy animals to the data file of animals with measured traits but with missing unmeasurable traits will result in the needed equations. At least two dummy records are needed to avoid a divide by zero error in calculating the sample standard deviation. The dummy records need to be associated with a level of at least one fixed factor. The dummy animals also must be added to the pedigree file with unknown sires and dams before running the program to obtain the inverse of the numerator relationship matrix (MTDFNRM). In the program to obtain solutions to the multiple trait mixed model equations (MTDFRUN), the full genetic (co)variance matrix, $\mathrm{G}_{\mathrm{N}}$, for both measured and unmeasured traits is needed. The residual (co)variance matrix must have zero covariances between pairs of measured and unmeasured traits but the variance of the unmeasured trait must not be zero. This procedure provides direct solutions for breeding values of unmeasured traits based on mixed model predictions of breeding values of the measured traits and also allows calculation of standard errors of prediction for the solutions directly from elements of the inverse of the augmented coefficient matrix. For example, this procedure can be used to predict breeding values of bulls (which have tenderness measurements) for the correlated trait of tenderness as a steer or heifer which cannot be measured on the bull.
\end{abstract}




\section{INTRODUCTION}

Breeding values of animals for traits which are not measured are often wanted; for example, breeding values of bulls for maternal traits such as milking ability. Although bulls do not have records, breeding values may be obtained through relationships with daughters that have records. If genetic and environmental covariances between measured trait(s) and unmeasured trait(s) are known, the mixed model equations (MME) can be augmented as described by Henderson $(1977,1984)$ to include unmeasured as well as measured traits. Henderson (1977) showed that augmenting the MME for unmeasured trait(s) results in solutions for breeding values which are best linear unbiased predictors, BLUP, and are independent of the genetic variances for the unmeasured traits. Prediction error variances as well as predicted breeding values can be obtained directly from the augmented MME.

\section{THE GENERAL MIXED MODEL}

The model for the measured traits is $\mathrm{y}=\mathrm{XB}+\mathrm{Zu}+\mathrm{e}$, with $\mathrm{E}(\mathrm{y})=\mathrm{XB}$ and

$$
\mathrm{V}\left[\begin{array}{l}
\mathrm{y} \\
\mathrm{u} \\
\mathrm{e}
\end{array}\right]=\left[\begin{array}{ccc}
\mathrm{V} & \mathrm{ZG} & \mathrm{R} \\
\mathrm{GZ} & \mathrm{G} & 0 \\
\mathrm{R} & 0 & \mathrm{R}
\end{array}\right] \text { where }
$$

$y$ is the vector of observations for measured traits, $B$ is the vector of fixed effects with incidence matrix $X, u$ is the vector of breeding values for measured traits with incidence matrix $\mathrm{Z}$, and $\mathrm{e}$ is the vector of random residuals.

BLUP of $u$ is known to be $\hat{\mathrm{u}}=\mathrm{GZ}^{\prime} \mathrm{V}^{-1}(\mathrm{y}-\mathrm{X} \hat{\beta})$ where $\hat{B}$ is the vector of solutions to the mixed model equations for the measured traits or equivalently of solutions to the generalized least squares equations.

As shown by Henderson (1977) for the vector of breeding values for the unmeasured trait, $u_{n}$, with $E\left(u_{n}\right)=0, V\left(u_{n}\right)=G_{n}$, and $\operatorname{Cov}\left(u, u_{n}^{\prime}\right)=C$, BLUP of $u_{n}$ is

$$
\begin{aligned}
\hat{\mathrm{u}}_{\mathrm{n}} & =\mathrm{C}^{\prime} \mathrm{Z}^{\prime} \mathrm{V}^{-1}(\mathrm{y}-\mathrm{X} \hat{\beta}) \\
& =\mathrm{C}^{\prime} \mathrm{G}^{-1} \mathrm{GZ}^{\prime} \mathrm{V}^{-1}(\mathrm{y}-\mathrm{X} \hat{\beta}) \\
& =\mathrm{C}^{\prime} \mathrm{G}^{-1} \hat{\mathrm{u}}
\end{aligned}
$$




\section{AUGMENTED MIXED MODEL EQUATIONS}

The augmented MME as described by Henderson (1977) are

where

$$
\left[\begin{array}{ccc}
X^{\prime} R^{-1} X & X^{\prime} R^{-1} Z & 0 \\
Z^{\prime} R^{-1} X & Z^{\prime} R^{-1} Z+W_{11} & W_{12} \\
0 & W_{12}^{\prime} & W_{22}
\end{array}\right]\left[\begin{array}{c}
\hat{\beta} \\
\hat{u} \\
\hat{u}_{n}
\end{array}\right]=\left[\begin{array}{c}
X^{\prime} R^{-1} y \\
Z^{\prime} R^{-1} y \\
0
\end{array}\right]
$$

$$
\left(\begin{array}{ll}
W_{11} & W_{12} \\
W_{12}^{\prime} & W_{22}
\end{array}\right)=\left(\begin{array}{ll}
G & C \\
C^{\prime} & G_{n}
\end{array}\right)^{-1}
$$

If the equations for $\hat{u}_{n}$ are absorbed, then because $\mathrm{W}_{11}-\mathrm{W}_{12} \mathrm{~W}_{22}^{-1} \mathrm{~W}_{12}^{\prime}=\mathrm{G}^{-1}$, the results are the usual MME for û, i.e., û for the augmented equations is the same as BLUP for $\mathrm{u}$ from the usual MME. The solutions for $\hat{\mathrm{u}}_{\mathrm{n}}$ from the augmented MME can be shown to be BLUP (Henderson, 1977) as follows:

From the last row of the augmented MME, $\hat{\mathrm{u}}_{\mathrm{n}}=-\mathrm{W}_{22}^{-1} \mathrm{~W}_{12}^{\prime} \hat{\mathrm{u}}$.

From multiplication of a matrix by its inverse $\mathrm{W}_{12}^{\prime} \mathrm{G}+\mathrm{W}_{22} \mathrm{C}^{\prime}=0$.

Thus, $\mathrm{W}_{12}^{\prime}=-\mathrm{W}_{22} \mathrm{C}^{\prime} \mathrm{G}^{-1}$, so that $\hat{\mathrm{u}}_{\mathrm{n}}=-\mathrm{W}_{22}^{-1}\left(-\mathrm{W}_{22} \mathrm{C}^{\prime} \mathrm{G}^{-1}\right) \hat{\mathrm{u}}=\mathrm{C}^{\prime} \mathrm{G}^{-1} \hat{\mathrm{u}}$ which is BLUP and does not depend on $G_{n}$.

\section{A PROGRAM TO FORM THE AUGMENTED EQUATIONS}

MTDFREML (Multiple Trait Derivative Free Restricted Maximum Likelihood) is a set of programs developed by Boldman et al. (1993) to solve the MME and to obtain REML estimates of variance components with a derivative-free algorithm. To augment the MME for the unmeasured traits requires modifications to input of two of the three MTDFREML programs. First, the preparation program (MTDFPREP) must be tricked to set up equations for breeding values of the unmeasured traits. Adding dummy records for the unmeasured traits but with missing records for the measured traits for dummy animals to the data file of animals with measured traits but with missing unmeasurable traits will result in the needed equations. The dummy animals also must be added to the pedigree file with unknown sires and dams before running the program (MTDFNRM) to obtain the inverse of the numerator relationship matrix.

The objective of this paper is to demonstrate the modifications to input to the MTDFREML programs that are required to implement Henderson's method of augmentation. 


\section{MATERIALS AND METHODS}

An example is used to demonstrate how the MME can be augmented as described by Henderson to include unmeasured traits. Various tenderness measures on meat of bulls will be used to predict breeding values for market animal tenderness. The MME are augmented to include market animal tenderness, the unmeasured trait.

Data came from the Germ Plasm Evaluation Project of the U.S. Meat Animal Research Center, Clay Center, NE, where 127 bulls and 1400 steers and heifers were measured for taste panel tenderness (T) and Warner Bratzler Shear Force (SF). Genetic and environmental covariance matrices including measured and unmeasured traits are needed and must be previously estimated, in this case from 1400 measures on related steers and heifers (market animals). These covariance matrices will then provide the basis for the following analysis.

Covariances for this example are between two measured traits, $\mathrm{T}$ and SF, and the unmeasured trait, $T^{*}$. The MME in MTDFREML must be augmented to include equations for each bull for $\mathrm{T}^{*}$, the unmeasured trait. The original observation vector, $\mathrm{y}$, includes only SF and $\mathrm{T}$ :

$$
y^{\prime}=\left[\begin{array}{ll}
y_{S F}^{\prime} & y_{T}^{\prime}
\end{array}\right]
$$

The model included fixed effects for birth year, breed, covariates for fraction heterozygosity, weaning age and number of days on feed.

\section{AUGMENTING THE MME IN MTDFREML}

To augment the MME to include equations for $T^{*}$, two of the MTDFREML programs must be tricked. At least two dummy records with $\mathrm{T}^{\star}$ measurements but with missing values for $\mathrm{SF}$ and $\mathrm{T}$ are needed to set up the needed equations. The following are the modifications to the input for MTDFPREP, MTDFNRM and MTDFRUN.

\section{INPUT TO MTDFNRM}

1) Add to pedigree file, the identification numbers for the two dummy animals with zeroes for each sire and dam.

\section{INPUT TO MTDFPREP}

2) Make sure there is a field in the data file for the unmeasured trait.

a) For real animals (bulls) with measured traits, the field for the unmeasured trait must contain the missing observation indicator, e.g., -99 . 
b) For the dummy animals

i) The fields for traits measured on the real animals (bulls) must contain the missing observation indicator, e.g., -99 .

ii) The field for the trait not measured on the real animals must contain a dummy measurement.

iii) At least one field corresponding to fixed effects must contain a level to correspond to a fixed effect for the dummy measurements on the dummy animals.

\section{INPUT TO MTDFRUN}

3) Elements of covariance matrices (use option 4 for solutions to MME)

a) Elements of the genetic covariance matrix among all measured traits and the unmeasured trait must be entered. The correct genetic variance of the unmeasured trait is needed for correct prediction error variances. Otherwise any non-zero entry will work if the full genetic covariance matrix is positive definite.

b) Environmental covariances between unmeasured trait and each measured trait are entered as ZEROs. Environmental variance of unmeasured trait can be any positive value. The correct matrix of covariances among environmental effects of measured traits is needed.

These modifications to the input of the MTDFREML programs result in the following equations for breeding values for the measured traits as well as the unmeasured traits:

Shear force for bulls (records)

Tenderness for bulls (records)

Tenderness for bulls as market animals (unmeasured)

Shear force as a bull for the dummy animals (unmeasured)

Tenderness as a bull for the dummy animals (unmeasured)

Tenderness for the dummy animals (dummy records) 
This procedure leads to two independent sets of equations: the augmented mixed model equations and an independent set of equations for the dummy animals. This independence is shown symbolically.

Left hand sides of augmented and other set of MME are shown here symbolically before adding $\left(\begin{array}{ll}G & C \\ C & G_{n}\end{array}\right)^{-1}$

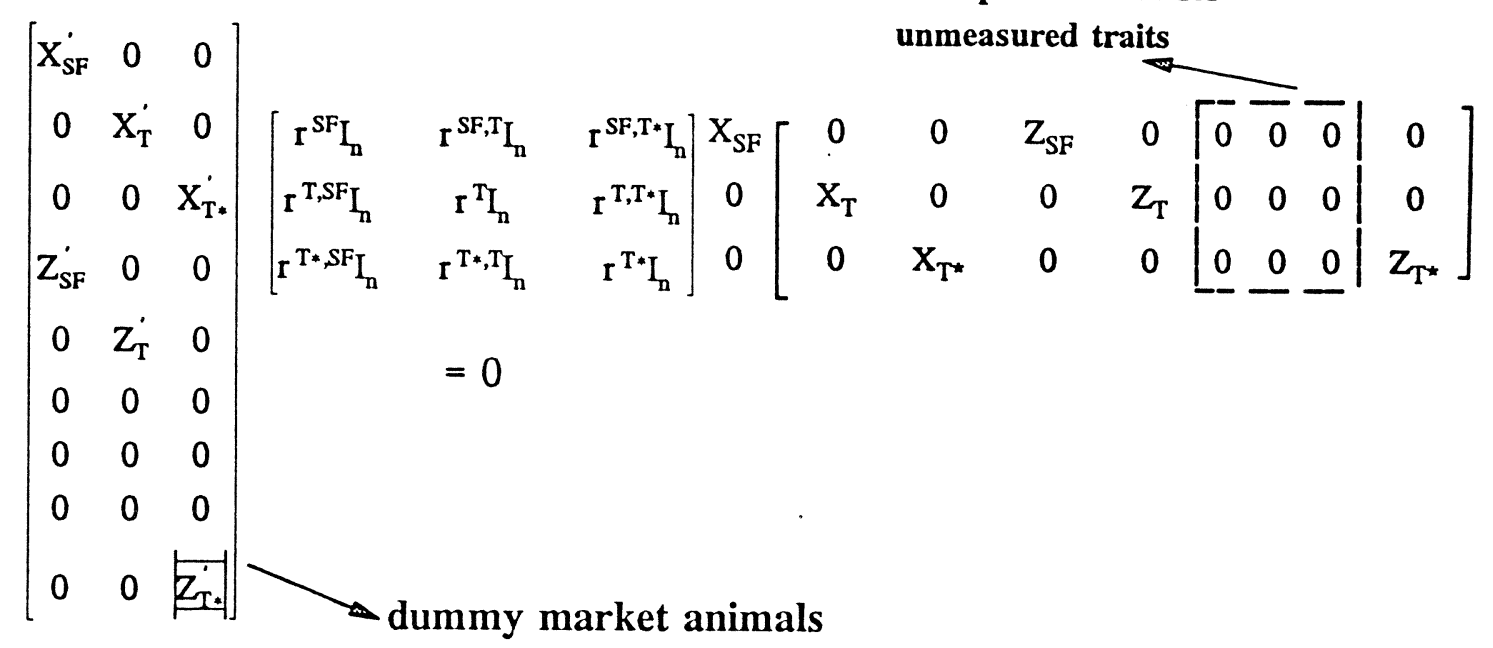

The equations for $\mathrm{SF}$ and $\mathrm{T}$ are linked by $\mathrm{r}^{\mathrm{SF}, \mathrm{T}}$, but equations for $\mathrm{T}^{*}$ are not linked to either bull trait $\left(\mathrm{r}^{\mathrm{SF}}, \mathrm{T}^{\star}, \mathrm{r}^{\mathrm{T}}, \mathrm{T}^{\star}=0\right)$. As a result, the augmented left hand sides (LHS) are two independent sets of equations, one for the measured bull traits and the other representing the dummy animals with dummy market animal tenderness records. 
The following portion of the LHS represents Henderson's augmented equations after adding $\left(\begin{array}{ll}G & C \\ C & G_{n}\end{array}\right)^{-1}$ to the highlighted box in the previous
equations.

The zeros represent coefficients of equations for bull tenderness as a market animal (unmeasured).

$$
\left[\begin{array}{cccc}
\left(\begin{array}{ccc}
Z_{S F}^{\prime} r^{S F} Z_{S F} & Z_{S F}^{\prime} r^{S F, T} Z_{T} & 0 \\
Z_{T}^{\prime} r^{S F, T} Z_{S F} & Z_{T}^{\prime} r^{T} Z_{T} & 0 \\
0 & 0 & 0
\end{array}\right)+\left(G_{0}^{+}\right) \otimes A^{-} & 0_{3 \times 3} \\
& \\
0_{3 \times 3} & & \left(\begin{array}{lll}
0 & 0 & 0 \\
0 & 0 & 0 \\
0 & 0 & Z_{T^{\prime}}^{\prime} r^{T^{*}} Z_{T^{*}}
\end{array}\right)+\left(G_{0}^{+}\right) \otimes 1
\end{array}\right]
$$

The other elements result from tricking the programs to include the unmeasured traits. 


\section{RIGHT HAND SIDES (RHS) OF MME CORRESPONDING TO THE LHS:}

$$
\left[\begin{array}{ccc}
\mathrm{X}_{\mathrm{SF}}^{\prime} & 0 & 0 \\
0 & \mathrm{X}_{\mathrm{T}}^{\prime} & 0 \\
0 & 0 & \mathrm{X}_{\mathrm{T} *}^{\prime} \\
\mathrm{Z}_{\mathrm{SF}}^{\prime} & 0 & 0 \\
0 & \mathrm{Z}_{\mathrm{T}}^{\prime} & 0 \\
0 & 0 & 0 \\
0 & 0 & 0 \\
0 & 0 & 0 \\
0 & 0 & \mathrm{Z}_{\mathrm{T} *}^{\prime}
\end{array}\right]\left[\begin{array}{ccc}
\mathrm{r}^{\mathrm{SF}} \mathrm{I}_{\mathrm{n}} & \mathrm{r}^{\mathrm{SF}, \mathrm{T}_{\mathrm{n}}} & \mathrm{r}^{\mathrm{SF}, \mathrm{T} *} \mathrm{I}_{\mathrm{n}} \\
\mathrm{r}^{\mathrm{T}, \mathrm{SF} \mathrm{I}_{\mathrm{n}}} & \mathrm{r}^{\mathrm{T} \mathrm{I}_{\mathrm{n}}} & \mathrm{r}^{\mathrm{T}, \mathrm{T}^{*} \mathrm{I}_{\mathrm{n}}} \\
\mathrm{r}^{\mathrm{T}, \mathrm{SF}_{\mathrm{n}}} & \mathrm{r}^{\mathrm{T}, \mathrm{T} \mathrm{I}_{\mathrm{n}}} & \mathrm{r}^{\mathrm{T} *} \mathrm{I}_{\mathrm{n}}
\end{array}\right]\left[\begin{array}{c}
\mathrm{y}_{\mathrm{SF}} \\
\mathrm{y}_{\mathrm{T}} \\
\mathrm{y}_{\mathrm{T} *}
\end{array}\right]
$$

After symbolic multiplication, the right hand sides and corresponding solution vector, become:

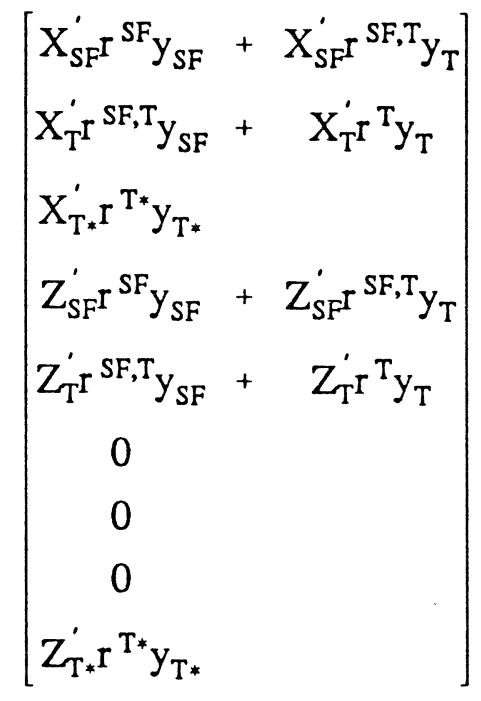

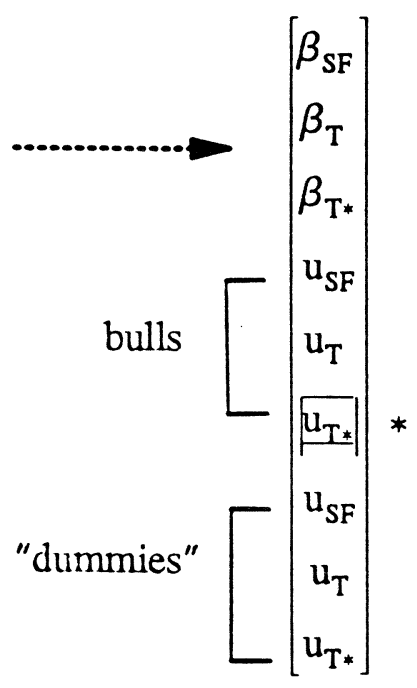

${ }^{*}$ where $\mathrm{u}_{\mathrm{T}^{*}}$ represents the desired breeding values of bulls for $\mathrm{T}^{\star}$, which was not measured on the bulls.

Examination of these equations reveals the augmented equations to predict breeding values for unmeasured trait and an independent set of equations resulting from the dummy records of the dummy animals. 
THE ESTIMATES OF COVARIANCES AMONG SF, T, AND T* USED FOR THE EXAMPLE ARE:

$$
\mathrm{G}_{\mathrm{N}}^{+}=\left[\begin{array}{ccc}
\mathrm{SF} & \mathrm{T} & \mathrm{T} * \\
.619 & -.082 & -.122 \\
-.082 & .015 & .040 \\
-.122 & .040 & .174
\end{array}\right]
$$

and

$$
\mathrm{R}_{0}^{+}=\left[\begin{array}{ccc}
\mathrm{SF} & \mathrm{T} & \mathrm{T} * \\
1.383 & -.686 & 0 \\
-.686 & .643 & 0 \\
0 & 0 & 1.527
\end{array}\right]
$$

\section{RESULTS}

Range of predicted breeding values of the bulls for market animal tenderness was small due to the lack of genetic variation in tenderness, -.11 to .08 .

A typical prediction error variance from option 4 of MTDFRUN was $(.39)^{2}=$ .1521 so that the average squared correlation between true and predicted breeding value for market animal tenderness of bulls measured for tenderness and shear force is $r_{\mathrm{Tr}}^{2}=1$ $(.1521 / .174)=.13$ with accuracy $=.36$.

\section{CONCLUSIONS}

Input to the MTDFREML programs, can be modified to predict breeding values of animals for traits not in the model for records, e.g., prediction of breeding values of bulls for market animal tenderness.

\section{REFERENCES}

Boldman, K. G., L. A. Kriese, L. D. Van Vleck, and S. D. Kachman. 1993. A Manual for use of MTDFREML. A set of programs to obtain estimates of variances and covariances [DRAFT]. U.S. Department of Agriculture, Agricultural Research Service. pp 120.

Henderson, C. R. 1977. Best linear unbiased prediction of breeding values not in the model for records. J. Dairy Sci. 60:783.

Henderson, C. R. 1984. Application of linear models in animal breeding. Univ. Guelph, Guelph, ON, Canada. 